\title{
Análise GGE biplot de genótipos de milho sob diferentes formas de adubação em sistema de agricultura familiar
}

\section{GGE biplot analysis of maize genotypes under different forms of fertilization in family farming system}

\author{
Eduardo Stefani Pagliosa ${ }^{1}$; Valéria Carpentieri-Pípolo ${ }^{2 *}$ \\ Claudemir Zucareli ${ }^{2}$; Valquíria Sheila Zago ${ }^{1}$
}

\begin{abstract}
Resumo
A interação genótipo $\mathrm{x}$ ambiente influencia grandemente a seleção de genótipos e o sistema de cultivo adotado deve levar em consideração a resposta do genótipo ao manejo empregado. O objetivo deste trabalho foi avaliar a interação genótipo $\mathrm{x}$ ambiente através da análise GGE biplot de quatro genótipos de milho (duas variedades crioulas, uma variedade melhorada e um híbrido comercial) em resposta a formas de adubação (orgânica e química) sob diferentes ambientes. O delineamento experimental foi de blocos ao acaso em esquema fatorial $5 \times 4 \times 3$, com quatro repetições, com a combinação dos fatores: cinco ambientes (Imbaú em 2006/2007; Alvorada do Sul em 2008/2009; e Londrina em 2007/2008, 2008/2009 e 2009/2010); quatro genótipos de milho (Caiano, Asteca, DKB 390 e IPR 114); e três formas de adubações (sem adubação, adubação orgânica e adubação química). Considerando o rendimento para Alvorada do Sul, o híbrido DKB 390 em cultivo com cama de frango é uma alternativa para pequenos produtores visando maiores produtividades. Para Londrina, a utilização de IPR 114 propicia maior produtividade, no sistema testado, entretanto para Imbaú deve-se utilizar Asteca. A avaliação dos efeitos da interação genótipo x ambiente baseada na análise GGE Biplot possibilitou identificar através do comportamento genotípico as variedades promissoras e estáveis, bem como os ambientes que otimizam o desempenho das variedades, sendo um método recomendado para melhorar a eficiência da identificação de genótipos em ambientes específicos.
\end{abstract}

Palavras-chave: Zea mays, adubação orgânica, interação genótipo x ambiente

\begin{abstract}
Genotype $\mathrm{x}$ environment interaction greatly influences the selection of genotypes and the crop system should take into account the response of genotype to the employee management. The aim of this experiment was to evaluate the genotype $\mathrm{x}$ environment interaction by GGE biplot analysis of four maize varieties (landrace, improved variety and commercial hybrid) in response to fertilization treatments (organic and chemical) under different environments. The experimental was in a $5 \times 4 \times 3$ factorial randomized block design with four replications, with the combination of factors: five environments (Imbaú in 2006/2007; Alvorada do Sul in 2008/2009, and Londrina in 2007/2008, 2008/2009 and 2009/2010), four maize genotypes (Caiano, Azteca, DKB 390 and IPR 114) and three types of fertilization (without fertilizer, organic and chemical fertilizer). Considering the yield to Alvorada do Sul hybrid DKB 390 in cultivation with poultry litter is an alternative for small farmers. To Londrina using IPR 114 provides greater productivity for smallholders, however growers should use Azteca for Imbaú. The evaluation of the effects of genotype $\mathrm{x}$ environment interaction based on GGE Biplot analysis enabled us to identify
\end{abstract}

1 Eng $^{\text {os }}$ Agros $^{\text {os }}$ Mestres, Dept ${ }^{\circ}$ de Agronomia, Universidade Estadual de Londrina, Centro de Ciências Agrárias, UEL/CCA, Londrina, PR. E-mail: eduardopagliosa@gmail.com; kiaszago@yahoo.com.br

2 Eng ${ }^{\text {os }}$ Agr ${ }^{\text {os }}$, Drs., Dept ${ }^{\circ}$ de Agronomia, UEL/CCA, Londrina, PR. E-mail: valeriacarpentieri@gmail.com; claudemircca@uel.br * Autor para correspondência 
behavior through promising and stable genotypic varieties as well as environments that optimize the performance of varieties, being a recommended method to improve the efficiency of the identification of genotypes for specific environments.

Key words: Zea mays, organic fertilizer, genotype $\mathrm{x}$ environment interaction

\section{Introdução}

Variedades crioulas apresentam inúmeras vantagens para agricultores familiares, como por exemplo, semente de baixo custo, qualidade conhecida e por estar prontamente disponível. Variedades crioulas de milho têm sido cultivadas por várias gerações por serem adaptadas às condições agro-ecológicas locais e apresentam, principalmente em ambientes de baixa tecnologia genes de resistência à fatores bióticos e abióticos como bom empalhamento e rendimento de grãos (ARAÚJO; NASS, 2002; CARPENTIERI-PÍPOLO et al., 2010). A grande variabilidade genética é o principal fator que garante a essas variedades elevada adaptação aos ambientes onde foram desenvolvidas (MAXTED; FORD-LLOYD; HAWKES, 1997).

As interações genótipo $\mathrm{x}$ ambiente (GxA) são um dos principais fatores que limitam a eficiência dos programas de melhoramento. A maior parte do processo de seleção ocorre nas estações de pesquisa, desconsiderando-se que a seleção para a adaptação específica é particularmente importante em culturas que são produzidas predominantemente em condições desfavoráveis, porque em ambientes desfavoráveis podem ser muito diferentes umas das outras, enquanto que nos ambientes favoráveis tendem a ser similares (CECCARELLI; GRANDO, 1997). Embora seja reconhecida a importância das variedades crioulas como fonte de alelos para tolerância a estresses bióticos e abióticos e sua importância para sistemas de agricultura familiar, poucos são os estudos de análise das interações genótipo $\mathrm{x}$ ambiente sobre essas cultivares.

A estimativa do rendimento de cada cultivar em cada ambiente teste é uma medida do efeito do ambiente (A), do efeito do genótipo (G), e do efeito da interação GxA (YAN; TINKER, 2006). Normalmente o ambiente explica $80 \%$ ou mais da variação do rendimento. No entanto, é o genótipo e a interação genótipo $\mathrm{x}$ ambiente que são relevantes para a avaliação dos cultivares (YAN, 2002). Várias metodologias tem sido propostas para analisar a interação GxA, por exemplo, métodos univariados como coeficiente de variabilidade de Francis e Kannenberg, componentes da variância de Plaisted \& Peterson, ecovalência de Wricke, a variância; estabilidade da variância de Shukla, coeficiente de regressão de Finlay e Wilkinson, coeficiente de regressão Perkins e Jinks, e soma dos desvios quadrados de regressão de Eberhart e Russell (RAO et al., 2011).

Normalmente, um grande número de genótipos são avaliados em uma série de ambientes (locais e anos) e muitas vezes é difícil determinar o padrão de resposta genotípica em locais ou épocas sem a ajuda de visualização gráfica dos dados (YAN, 2001). A análise GGE biplot (genotype and genotype-byenvironment), mais adaptada à modelos biológicos que outras análises gráficas, fornece a solução para o problema acima e têm sido amplamente utilizada para visualizar a interação GxA uma vez que permite a visualização da inter-relação entre os ambientes, genótipos, e da interação entre ambos (YAN et al., 2000).

A proposta deste trabalho foi de avaliar a interação genótipo $\mathrm{x}$ ambiente, através da análise GGE biplot de variedades de milho (variedades crioulas, variedade melhorada e híbrida) em resposta a formas de adubação (orgânica, química ou sem adubação) e sob diferentes ambientes, com vistas à tomada de decisões quanto à recomendação de variedades e formas de adubação para agricultura familiar. 


\section{Material e Métodos}

O experimento foi conduzido em três locais, em diferentes safras agrícolas: Assentamento Guanabara em Imbaú (2006/2007; em 2426'S e $\left.50^{\circ} 45^{\prime} \mathrm{O}\right)$, Assentamento Iraci Salete em Alvorada do

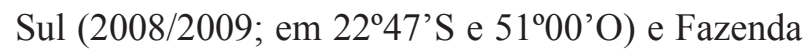
Experimental da Universidade Estadual de Londrina, Londrina (2006/2007, 2008/2009 e 2009/2010; em $23^{\circ} 23^{\prime}$ S e $\left.51^{\circ} 11^{\prime} \mathrm{W}\right)$. Imbaú, Alvorada do Sul e Londrina apresentam, respectivamente, altitude média de $940 \mathrm{~m}, 380 \mathrm{~m}$ e $600 \mathrm{~m}$. O solo predominante em Imbaú, Alvorada do sul e Londrina são Cambissolo Háplico distrófico com textura argilosa, Latossolo Roxo eutrófico e Latossolo Vermelho distroférrico, respectivamente (EMBRAPA, 1999). O clima das três localidades é classificado como Cfa segundo Köppen (CAVIGLIONE et al., 2000). As características químicas do solo de cada local em cada safra, coletadas a uma profundidade de 0,2 $m$ e determinadas analiticamente, encontram-se na Tabela 1.

Tabela 1. Análise química da amostra de solo dos diferentes ambientes.

\begin{tabular}{|c|c|c|c|c|c|c|c|c|c|c|}
\hline \multirow{2}{*}{ Local/Ano } & pH & $\mathbf{P}$ & $\mathbf{K}$ & $\mathbf{C a}$ & Mg & Al & $\mathbf{H}+\mathbf{A l}$ & \multirow[t]{2}{*}{ SB } & \multirow{2}{*}{$\begin{array}{c}\text { CTC } \\
\text { pH 7,0 }\end{array}$} & \multirow[t]{2}{*}{$\mathrm{V} \%$} \\
\hline & $\mathrm{CaCl}_{2}$ & $\mathrm{mg} \mathrm{dm}^{-3}$ & \multicolumn{5}{|c|}{$\mathrm{cmol}_{c} \mathrm{dm}^{-3}$ de solo } & & & \\
\hline Imbaú 2006/2007 & 5,13 & 3,04 & 0,44 & 5,24 & 1,42 & 0,36 & 5,97 & 7,13 & 13,10 & 53,48 \\
\hline Londrina 2006/2007 & 5,13 & 19,56 & 0,22 & 4,63 & 1,63 & 0,00 & 3,84 & 6,48 & 10,32 & 62,65 \\
\hline Alvorada do Sul 2008/2009 & 5.82 & 47.55 & 1,49 & 18,28 & 6,84 & 0,00 & 5,11 & 26,65 & 31,76 & 83,88 \\
\hline Londrina 2008/2009 & 5,01 & 16,52 & 0,53 & 3,17 & 0,86 & 0,13 & 6,72 & 4,55 & 11,27 & 40,42 \\
\hline Londrina $2009 / 2010$ & 4,90 & 11,00 & 0,59 & 5,07 & 1,89 & 0,04 & 6,68 & 7,55 & 14,23 & 53,05 \\
\hline
\end{tabular}

pH: Potencial de Hidrogênio; P: Fósforo; K: Potássio; Ca: Cálcio; Mg: Magnésio; Al: Alumínio; H: Hidrogênio; SB: Soma de bases; CTC: Capacidade de troca de cátions; V\%: Saturação de bases.

Fonte: Elaboração dos autores.

O delineamento experimental foi o de blocos ao acaso em esquema fatorial $5 \times 4 \times 3$, com quatro repetições, com a combinação dos fatores: cinco ambientes (Imbaú 2006/2007; Londrina 2006/2007; Alvorada 2008/2009; Londrina 2008/2009; Londrina 2009/2010); quatro genótipos de milho: duas variedades crioulas (Caiano e Asteca), procedentes de pequenos agricultores do Norte do Paraná; uma de milho híbrido simples (DKB 390); e uma variedade melhorada de polinização aberta do IAPAR (IPR 114); e três fertilizantes (orgânico, mineral e sem adubação). As diferenças entre os caracteres dos genótipos estão descritos na Tabela 2. Como adubo orgânico utilizou-se cama de frango, distribuído a lanço na parcela, na proporção de $8,0 \mathrm{Mg} \mathrm{ha}^{-1}$; para a adubação mineral (NPK) foram utilizados $375 \mathrm{~kg} \mathrm{ha}^{-1}$ do formulado 08-28-16, distribuído diretamente no sulco de semeadura. As análises de teores de nutrientes da adubação orgânica apresentaram 2,36\%, 2,57\% e $3,24 \%$ para teores de nitrogênio, fósforo e potássio, respectivamente. Na testemunha não foi realizada nenhum tipo de adubação.

A semeadura foi realizada sempre na primeira quinzena de outubro. Cada parcela do experimento foi caracterizada por quatro fileiras de 5 metros de comprimento, com um espaçamento de $0,9 \mathrm{~m}$ entre fileiras e $0,2 \mathrm{~m}$ entre plantas. Para coleta de dados em campo e colheita foram utilizadas as duas linhas centrais de cada parcela.

Os preparos das áreas foram realizados mediante uma aração e duas gradagens. A semeadura e os tratos culturais foram realizados de acordo com recomendações para o cultivo do milho (CRUZ, 2006): utilizou-se imidacloprido e tiodicarbe para o tratamento de sementes; foram realizadas duas capinas manuais; e aplicação de inseticida a base de 
alfa-cipermetrina e teflubenzurom para controle da lagarta do cartucho (Spodoptera frugiperda). Não foi realizada adubação nitrogenada de cobertura.

A colheita foi realizada quando os grãos estavam com aproximadamente 180 gramas de água por quilograma de grãos. Foi avaliado o rendimento de grãos (RG), determinado pela colheita e trilha de todas as plantas da parcela útil, em gramas, corrigido por 130 gramas de água por quilograma de grãos e transformado para $\mathrm{kg} \mathrm{ha}^{-1}$.

Tabela 2. Características dos genótipos de milho avaliados.

\begin{tabular}{lcccc}
\hline \multirow{2}{*}{ Caracteres } & \multicolumn{3}{c}{ Genótipos } \\
\cline { 2 - 5 } & Caiano & Asteca & DKB 390 & IPR 114 \\
\hline Tipo & Crioulo & Crioulo & Híbrido Simples & Variedade melhorada \\
Ciclo & & Precoce & Precoce \\
Graus Dias & & 871 & 870 \\
Uso & & & Grãos & Grãos \\
Cor do grão & Amarelo & Amarelo & Amarelo/alaranjado & Amarelo \\
Densidade (Plantas ha $\left.{ }^{-1}\right)$ & & & $55 / 65$ & 55 \\
Textura do Grão & Dentado & Dentado & Semi duro & Semi duro \\
Resistência ao acamamento & Baixa & Baixa & Alta & Moderada \\
Altura de espiga(m) & 1,7 & 2,0 & 1,25 & 1,15 \\
Altura de planta (m) & 2,4 & 3,0 & 2,2 & 2,2 \\
Nível de tecnologia & Baixo & Baixo & Alto & Médio \\
Empresa & & & Monsanto & IAPAR \\
\hline
\end{tabular}

Fonte: Elaboração dos autores.

Os dados foram submetidos à análise de homogeneidade de variância (Teste de Bartllet) e de normalidade (Lilliefors). Como as variâncias foram homogêneas e normais, procedeu-se às análises de variância, sem necessidade de transformação. Realizou-se uma análise conjunta, considerando ambientas como fator aleatório, e genótipos e tipos de fertilizante como fatores fixos, em esquema fatorial $5 \times 4 \times 3$. A relação entre o maior e o menor quadrado médio residual dos ambientes (QMr+/ QMr-) foi superior a sete, impossibilitando a utilização da análise conjunta dos dados. PimentelGomes (1990) relata que, se a relação entre o maior e o menor quadrado médio residual for menor do que sete, quase sempre a análise conjunta poderá ser efetuada sem maiores problemas. Entretanto, quando essa relação for muito além de sete, convém analisar separadamente subgrupos de experimentos com quadrados médios residuais não muito heterogêneos. Desta forma, cada ambiente foi considerado em separado. Para cada ambiente realizou-se a análise da variância considerando tanto genótipos quanto tipos de fertilizantes como fatores fixos, e em esquema fatorial $4 \times 3$. As médias foram comparadas pelo teste de Tukey a 5\% de probabilidade de erro. As análises foram realizadas no aplicativo computacional Genes (CRUZ, 2013).

Havendo interações significativas entre genótipos e adubações, a adaptação dos genótipos às adubações procedeu-se a análise GGE biplot (Genotype and Genotype-by-Environment), descrita por Yan et al. (2000), que permite o exame visual das relações entre os ambientes, entre os genótipos e das interações entre genótipo e ambiente (GxA). A análise GGE biplot foi realizada através do aplicativo computacional GGE biplot versão demo (YAN, 2001). 


\section{Resultados e Discussão}

Os resultados da análise de variância (Tabela 3) revelaram significância $(\mathrm{p}<0,05)$ para a interação dupla dos fatores genótipo x adubação, para rendimento de grãos, apenas para Alvorada do Sul na safra 2008/2009, indicando que os genótipos responderam de forma diferenciada aos tipos de adubação utilizados neste local. Houve resposta significativa e diferencial entre genótipos em todos os locais/anos, bem como significância para o fator principal de tipos de adubações para Imbaú
2006/2007, Alvorada do Sul 2008/2009 e Londrina 2008/2009. Os coeficientes de variação oscilaram entre $11,64 \%$ e $17,83 \%$, conferindo boa precisão às estimativas preditas neste estudo. Observase que as médias gerais obtidas em Londrina (safras 2006/2007, 2008/2009 e 2009/2010) foram superiores às observadas em Imbaú (2006/2007) e Alvorada do Sul (2008/2009), em função de Londrina ser considerado um ambiente favorável a cultura do milho (GARBUGLIO et al., 2007), o que propicia maior produtividade.

Tabela 3. Resumo das análises de variância individuais para rendimento de grãos ( $\left.\mathrm{kg} \mathrm{ha}^{-1}\right)$ em quatro genótipos de milho avaliados em Imbaú (006/2007), Alvorada do Sul (2008/2009) e Londrina (2006/2007, 2008/2009/ e 2009/2010), Estado do Paraná.

\begin{tabular}{lcccccc}
\hline \multirow{2}{*}{ F.V. } & G.L. & Imbaú & Londrina & Alvorada do Sul & Londrina & Londrina \\
\cline { 3 - 7 } & & $2006 / 2007$ & $2006 / 2007$ & $2008 / 2009$ & $2008 / 2009$ & $2009 / 2010$ \\
\hline Blocos & 3 & 67814.32 & 1023648 & 80316.82 & 1778183 & 722043.65 \\
Adubações (A) & 2 & $343288.69^{* *}$ & $621828.76^{\text {NS }}$ & $497155.14^{* *}$ & $2913222.81^{*}$ & $1207858.12^{\text {NS }}$ \\
Genótipos (G) & 3 & $168069.39^{* *}$ & $33282353.56^{* *}$ & $728919.88^{* *}$ & $37867222.44^{* *}$ & $87156508.41^{* *}$ \\
A x G & 6 & $48996.56^{\text {NS }}$ & $893625.36^{\text {NS }}$ & $160712.92^{* *}$ & $281167.53^{\text {NS }}$ & $586208.39^{\text {NS }}$ \\
Resíduo & 33 & 25061.05 & 674402 & 39144.30 & 836137.9 & 606508.91 \\
\hline Média & & 1246.27 & 7053.97 & 1109.26 & 6968.77 & 6532.75 \\
C.V. $(\%)$ & 12.70 & 11.64 & 17.83 & 13.12 & 11.92 \\
\hline
\end{tabular}

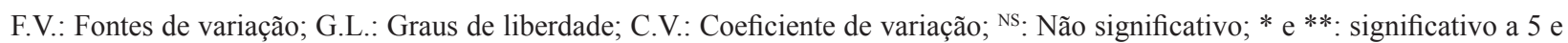
$1 \%$ de probabilidade pelo teste $\mathrm{F}$, respectivamente.

Fonte: Elaboração dos autores.

O hibrido DKB 390 apresentou desempenho superior aos demais genótipos em Imbaú 2009/2010 (1384,73 Kg ha ${ }^{-1}$ ) e Londrina 2006/2007 (9382,06 $\mathrm{Kg} \mathrm{ha-1)} \mathrm{(Tabela} \mathrm{4).} \mathrm{Entretanto,} \mathrm{em} \mathrm{Imbaú}$ 2006/2007 o genótipo DKB 390 não se diferenciou estatisticamente de Asteca (1296,65 Kg ha-1).
Diversos autores relatam que cultivares crioulas apresentam excelente adaptação em ambientes de estresse, ao contrário dos híbridos que apresentam a adaptabilidade restrita por serem desenvolvidos para cultivo em ambientes favoráveis (CARPENTIERIPÍPOLO et al., 2010; SOARES et al., 1998). 
Tabela 4. Rendimento de grãos $\left(\mathrm{kg} \mathrm{ha}^{-1}\right)$ médio por local/ano de quatro genótipos de milho.

\begin{tabular}{lcrrrrr}
\hline \multirow{2}{*}{ Genótipos } & \multicolumn{7}{c}{ Locais / Ano } \\
\cline { 2 - 6 } & Imbaú 2006/2007 & Londrina 2006/2007 & Londrina 2008/2009 & Londrina 2009/2010 \\
\hline Asteca & $1296.65 \mathrm{ab}^{1}$ & $6470.10 \mathrm{~b}$ & $5127.91 \mathrm{c}$ & $5471.50 \mathrm{~b}$ \\
Caiano & $1116.66 \mathrm{~b}$ & $5461.25 \mathrm{~b}$ & $6470.10 \mathrm{bc}$ & $3970.88 \mathrm{c}$ \\
DKB 390 & $1384.73 \mathrm{a}$ & $9382.06 \mathrm{a}$ & $6895.00 \mathrm{~b}$ & $6403.17 \mathrm{~b}$ \\
IPR 114 & $1187.04 \mathrm{~b}$ & $6902.50 \mathrm{~b}$ & $9382.05 \mathrm{a}$ & $10285.47 \mathrm{a}$ \\
\hline
\end{tabular}

Letras diferentes na coluna indicam diferenças significativas entre as médias pelo teste de Tukey, a 5\% de probabilidade de erro. Fonte: Elaboração dos autores.

As médias de rendimento de grãos dos genótipos em Imbaú 2006/2007 foram reduzidas comparadas com os demais locais/anos, principalmente em função da elevada quantidade de alumínio presente no solo (Tabela 1). A presença de elevada acidez e toxicidade por alumínio nos solos são fatores determinantes para a redução da produtividade das culturas. O alumínio inibe a divisão celular causando redução no volume e comprimento do sistema de raízes em plantas, prejudicando a absorção de nutrientes, reduzindo o aprofundamento das raízes, interferindo no desenvolvimento e reduzindo drasticamente a produtividade do milho (PATERNIANI; FORLANI, 2002; ALVES et al., 2004; HARTWIG et al., 2007). Para Imbaú, onde as condições de cultivo para a cultura do milho não são ideais, a utilização da variedade Asteca deve ser priorizada, uma vez que, segundo Bisognin et al. (1997) a utilização de variedades de polinização aberta é vantajosa economicamente para produtores que utilizam baixo investimento. Essa vantagem decorre do menor preço da semente, da possibilidade de utilizar as mesmas sementes por vários anos e da maior variabilidade genética das variedades em relação aos híbridos, característica que conferiria, às mesmas, maior tolerância a estresses bióticos e abióticos, comuns nas pequenas propriedades.

A variedade melhorada IPR 114 apresentou desempenho superior aos demais genótipos em Londrina 2008/2009 (9282,05 $\left.\mathrm{Kg} \mathrm{ha}^{-1}\right)$ e Londrina 2009/2010 (10285,47 Kg ha $\left.{ }^{-1}\right)$, evidenciando um elevado potencial produtivo (Tabela 4).
As médias de rendimentos de grãos encontradas no presente trabalho (de 1116,66 a $10285,47 \mathrm{~kg}$ ha ${ }^{1}$ ), apresentaram elevada amplitude comparadas às encontradas por Hemp et al. (2011) em trabalho realizado em Chapecó, SC, que avaliaram 19 variedades locais de milho com adubação orgânica onde o rendimento de grãos das variedades oscilou entre 4847 e $8128 \mathrm{~kg} \mathrm{ha}^{-1}$. Rabbers et al. (2009) em trabalho feito com quatro variedades de milho crioula em agricultura orgânica, em Marechal Candido Rondom, PR, encontraram grandes diferenças na produtividade das cultivares testadas, variando de 2972,88 $\mathrm{kg} \mathrm{ha}^{-1}$ até $6630,50 \mathrm{~kg} \mathrm{ha}^{-1}$.

Com relação ao efeito das formas de adubação (Tabela 5), as médias de rendimentos de grãos obtidas para Imbaú 2006/2007 foram de 1080,37, 1300,69 e 1357,75, para o tratamento sem adubação, cama de frango e adubação NPK, respectivamente. Entretanto, para Londrina 2008/2009 observaramse médias 7238,61, 7190,87 e 6476,82 kg ha-1, respectivamente para os três tipos de adubação. Para Imbaú 2006/2007 observa-se um rendimento de grãos superiores para adubação NPK, não diferindo para cama de frango. Apesar de não existir diferença estatística entre os tratamentos cama de frango e adubação NPK, a menor média de rendimento de grãos obtida com a aplicação de cama de frango pode ser explicada pela retenção no nitrogênio e, consequentemente, baixa disponibilidade durante o processo de degradação da matéria orgânica. Essa afirmação está de acordo com Kirchmann e Bernal (1997), que verificaram no tratamento com cama de frango, as baixas taxas de disponibilização de 
$\mathrm{N}$ em relação às fontes minerais, as quais foram explicadas pelo fato desta não ter sofrido o processo de estabilização antes da aplicação. O fertilizante é rico em nitrogênio proveniente das fezes e em carbono presente na maravalha, que ao entrar em contato com o solo, tem a atividade microbiana intensificada pela presença de alimento, resultando em aumento da decomposição e conseqüente déficit momentâneo de $\mathrm{N}$ disponível para as plantas.

Tabela 5. Rendimento de grãos médio de milho $\left(\mathrm{kg} \mathrm{ha}^{-1}\right)$ por local/ano em três diferentes formas de adubação.

\begin{tabular}{lrc}
\hline \multirow{2}{*}{ Adubações } & \multicolumn{3}{c}{ Locais / Ano } \\
\cline { 2 - 4 } & Imbaú 2006/2007 & Londrina 2008/2009 \\
\hline Sem adubação & $1080.37 \mathrm{~b}$ & $7238.61 \mathrm{a}$ \\
Cama de frango & $1300.69 \mathrm{ab}$ & $7190.87 \mathrm{a}$ \\
NPK & $1357.75 \mathrm{a}$ & $6476.82 \mathrm{~b}$ \\
\hline
\end{tabular}

(1) Letras diferentes na coluna indicam diferenças significativas entre as médias pelo teste de Tukey, a 5\% de probabilidade de erro. Fonte: Elaboração dos autores.

Considerando-se a sustentabilidade dos sistemas de exploração, a utilização de cama de frango pela disponibilidade na propriedade e o baixo custo quando comparada ao fertilizante químico é a alternativa mais viável para utilização no assentamento Guanabara, em Imbaú. A limitação em recomendação da cama de frango como fertilizante se dá devido à falta de padronização dos teores dos nutrientes. Blum et al. (2003) obtiveram valores da composição química da cama de frango de 2,82\%, $2,53 \%$ e $2,5 \%$ para N, P e Ca, respectivamente. Sangalli, Vieira e Zárate (2004) obtiveram teores de 29,4\%, 22,4\% 30,0\% para N, Pe K, respectivamente. Desta forma, fica evidente a elevada variação entre os teores de nutrientes encontrados pelos diferentes autores. Esta variação na composição mineral, possivelmente, é em função do tipo de material, número de lotes criados, lotação, sexo e manejo da cama utilizado em cada local ou região (ÁVILA et al., 2007).

Vale ressaltar o incremento da produtividade com a utilização da adubação orgânica $(7190,87$ $\left.\mathrm{kg} \mathrm{ha}^{-1}\right)$ em relação à adubação mineral (6476,82 $\mathrm{kg} \mathrm{ha}^{-1}$ ) obtido em Londrina 2008/2009, resultado que concorda com Maia e Cantarutti (2004), em trabalho realizado em Coimbra, MG, utilizando o cultivo de milho com diferentes doses de adubo orgânico e mineral por 13 anos, concluíram que o uso de adubação orgânica aumenta a produtividade de milho.

A porcentagem de explicação acumulada para Alvorada do Sul 2008/2009 foi de 100\%, onde o componente principal 1 (PC1) e o componente principal 2 (PC2) explicaram 70,2\% e 29,8\%, respectivamente, da variação total dos dados (Figuras 1 e 2). Tais valores conferem elevada confiabilidade na explicação da variação total do desempenho dos genótipos, mais a interação com o ambiente $(\mathrm{G}+\mathrm{GxA})$, representado pelo tipos de adubação empregado. Desta forma, a resposta produtiva dos genótipos de milho quanto aos tipos de adubação empregados podem ser explicadas pelo padrão retido nas análises gráficas, facilitando a visualização e interpretação dos dados (RAO et al., 2011). Segundo Benin et al. (2012) as técnicas biplot são eficientes em indicar genótipos mais adaptadas aos manejos empregados, com riqueza de detalhes quanto ao desempenho dos genótipos, sendo possível maximizar o potencial produtivo dos genótipos, minimizando os riscos. A redução dos riscos de perdas é um fator crucial para agricultores familiares, principalmente pequenos produtores, pois possibilita maior aproveitamento da sua propriedade e maior retorno econômico. Desta 
forma, é evidente a importância da correta indicação do genótipo para o tipo de adubação que propicia redução de riscos e maior produtividade.

Maior detalhamento do desempenho do rendimento de grãos dos genótipos de milho em Alvorada do Sul 2008/2209, em relação aos tipos de adubação, pode ser observado na Figura 1. Nesta análise, existe uma linha que passa pela origem do biplot e, ao longo desta, os genótipos são ranqueados em relação aos desempenhos para cada tipo de adubação (YAN; TINKER, 2006). Desta forma, os genótipos DKB 390 e IPR 114 apresentaram maior proximidade aos tipos de adubação, entretanto apresentado menor estabilidade produtiva, comparada a Caiano. Apenas o híbrido DKB 390 teve rendimento acima da média do gráfico biplot (Figura 1). Destaca-se o melhor desempenho de DKB 390, confirmando o que foi observado na análise de setores da figura 2, através do critério de megaambientes.

Figura 1. Plotagem dos escores dos componentes principais quanto à classificação dos genótipos com base em seu desempenho nos diferentes tipos de adubação, individualmente, segundo o modelo GGE Biplot, para o caractere rendimento de grãos de quatro genótipos de milho, avaliados em três tipos de adubação.

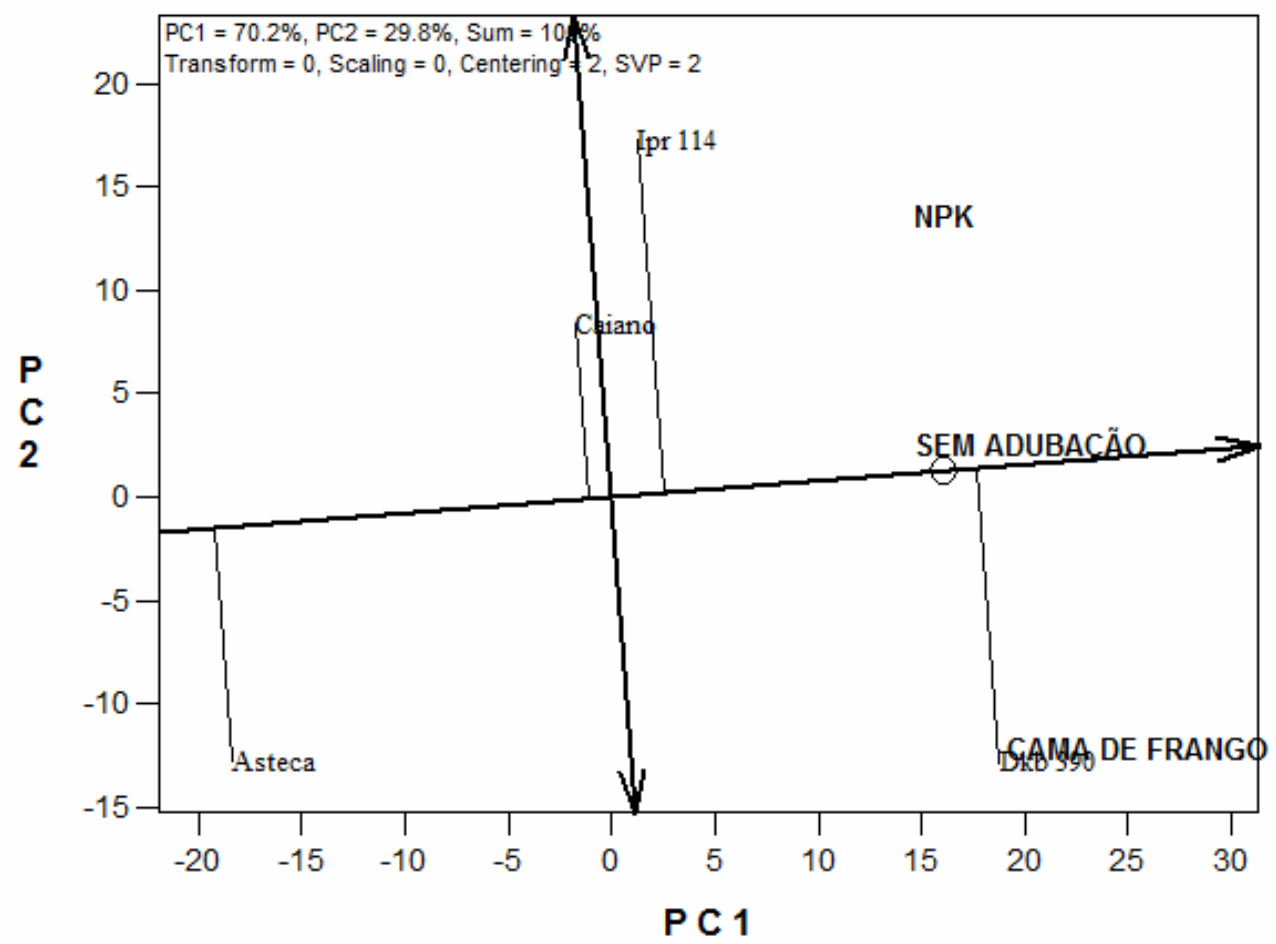

Fonte: Elaboração dos autores.

Os genótipos localizados nos vértices de cada setor apresentam o melhor ou o pior desempenho no referido setor (YAN; TINKER, 2006). A figura 2 apresenta o polígono do modelo GGE biplot para rendimento dos genótipos indicando o melhor genótipo para cada tipo de adubação. O polígono é formado pela conexão dos valores dos genótipos que estão mais distantes da origem do biplot de forma que todos os genótipos estão contidos dentro do polígono. IPR114 foi a variedade de melhor desempeno para adubação química NPK; DKB 390 foi a variedade de melhor desempenho na adubação orgânica, Asteca não se associou com nenhum tipo de adubação (Figura 2). 
Figura 2. Plotagem dos escores dos componentes principais quanto à indicação do tipo de adubação com médias setoriais de rendimento obtidas pelos tipos de adubação e genótipos presentes em cada setor, segundo o modelo GGE Biplot, do caractere rendimento de grãos de quatro genótipos de milho, avaliados em três tipos de adubação, em Alvorada do sul (2008/2009).

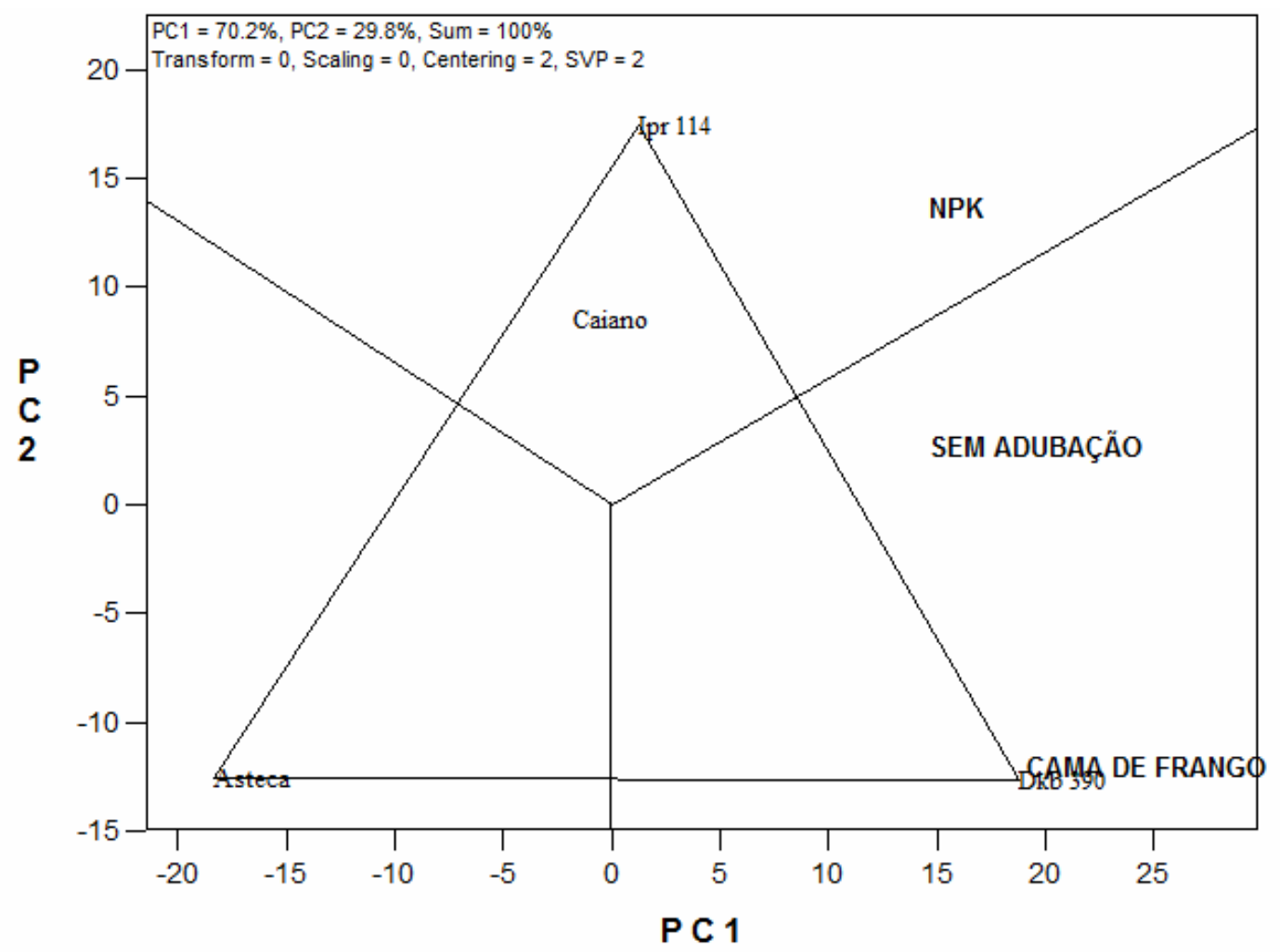

Fonte: Elaboração dos autores.

Neste contexto, os genótipos DKB 390 e IPR 114 têm melhor desempenho nos setores correspondentes. Por outro lado, o genótipo Asteca, também localizado no vértice, apresentou o pior desempenho no setor onde está localizado. Cabe salientar que Asteca não se associou com nenhum tipo de adubação. A limitação do GGE biplot é que raramente ele pode explicar somente uma pequena proporção do total como ocorreu com Asteca, pois uma premissa da análise GGE Biplot é não associar cultivares a quaisquer ambientes quando a média do genótipo for inferior à média da interação GxA de cada setor (YAN, 2001).

Ainda na Figura 2, observa-se que o genótipo IPR 114 está positivamente associado à adubação por NPK. Por outro lado, o genótipo DKB está positivamente associado, principalmente, à cama de frango, bem como à sem adubação. Desta forma, a utilização do híbrido DBK 390 com adubação de cama de frango pode contribuir na maximização da produtividade, através da maior resposta do genótipo a este manejo, menor custo e maior disponibilidade deste insumo, sendo uma alternativa viável para pequenos produtores de Alvorada do Sul.

\section{Conclusão}

Considerando o rendimento para Alvorada do Sul, o híbrido DKB 390 em cultivo com cama de frango é uma alternativa para pequenos produtores visando maiores produtividades.

Para Londrina a utilização de IPR 114 propicia maior produtividade para os pequenos produtores, entretanto para Imbaú deve-se utilizar Asteca. 
A análise gráfica do método GGE Biplot possibilitou identificar através do comportamento genotípico as variedades promissoras e estáveis, bem como os ambientes que otimizam o desempenho das variedades, sendo um método recomendado para melhorar a eficiência da identificação de genótipos à ambientes específicos.

\section{Agradecimentos}

Os autores agradecem a Coordenação de Aperfeiçoamento de Pessoal de Nível Superior (CAPES) pelo auxílio financeiro.

\section{Referências}

ALVES, V. M. C.; PITTA, G. V. E.; PARENTONI, S. N.; SCHAFFERT, R. E.; COELHO, A. M.; MAGALHÃES, J. V. Toxidez por alumínio e hidrogênio no crescimento de raízes de milho. Revista Brasileira de Milho e Sorgo, Sete Lagoas, v. 3, n. 2, p. 311-318, 2004.

ARAÚJO, P. M.; NASS, L. L. Caracterização e avaliação de populações de milho crioulo. Scientia Agricola, Piracicaba, v. 59, n. 3, p. 589-593, 2002.

ÁVILA, V. S.; ABREU, V. M. N.; FIGUEIREDO, E. A. P.; BRUM, P. A. R.; OLIVEIRA, U. Valor agronômico da cama de frangos após reutilização por vários lotes consecutivos. Concórdia: Embrapa Suínos e Aves, 2007. 4 p. (Comunicado técnico, 466).

BENIN, G.; PINNOW, C.; LEMES DA SILVA, C.; PAGLiOSA, E. S.; BECHE, B.; ELESANDRO BORNHOFEN, E.; MUNARO, L. B.; SILVA, R. R. Análises biplot na avaliação de cultivares de trigo em diferentes níveis de manejo. Bragantia, Campinas, v. 71, n. 1, p. 28-36, 2012.

BISOGNIN, D. A.; CIPRANDI, O.; COIMBRA, J. L. M.; GUIDOLIN, A. F. Potencial de variedades de polinização aberta de milho em condições adversas de ambiente. Pesquisa Agropecuária Gaúcha, v. 3, n. 1, p. 29-34, 1997.

BLUM, L. E. B.; AMARANTE, C. V. T.; GÜTTLER, G.; MACEDO, A. F.; KOTHE, D. M.; SIMMLER, A. O.; PRADO, G.; GUIMARÃES, L. S. Produção de moranga e pepino em solo com incorporação de cama aviária e casca de pinus. Horticultura Brasileira, Brasília, v. 21, n. 4, p. 627-631, 2003.
CARPENTIERI-PÍPOLO, V. C.; SOUZA, A.; SILVA, D. A.; BARRETO, T. P.; GARBUGLIO, D. D.; FERREIRA, J. M. Avaliação de cultivares de milho crioulo em sistema de baixo nível tecnológico. Acta Scientiarum. Agronomy, Maringá, v. 32, n. 2, p. 229-233, 2010.

CAVIGLIONE, J. H.; KIIHL, L. R. B.; CARAMORI, P. H.; OLIVEIRA, D. Cartas climáticas do Paraná. Londrina: IAPAR, 2000. 1 CD-ROM.

CECCARELLI, S.; GRANDO, S. Increasing the efficiency of breeding through farmer participation. In: Ethics and equity in conservation and use of $\overline{\text { genetic }}$ resources for sustainable food security. Rome: IPGRI, 1997. p. 116-121.

CRUZ, C. D. GENES - a software package for analysis in experimental statistics and quantitative genetics. Acta Scientiarum. Agronomy, Maringá, v. 35, n. 3, p. 271-276, 2013.

CRUZ, J. C. Cultivo do milho. Sistemas de produção 1. Embrapa Milho e Sorgo. Versão eletrônica, 2006. Disponível em: <http://www.cnpms.embrapa.br/ publicacoes/milho_6_ed/index.htm>. Acesso em: 08 maio 2012.

EMPRESA BRASILEIRA DE PESQUISA AGROPECUÁRIA - EMBRAPA. Centro nacional de pesquisas de solos. Sistema brasileiro de classificação de solos. Rio de Janeiro: Embrapa, 1999. 412 p.

GARBuglio, D. D.; GERAGE, A. C.; ARAÚJO, P. M.; FONSECA JUNIOR, N. S.; SHIOGA, P. S. Análise de fatores e regressão bissegmentada em estudos de estratificação ambiental e adaptabilidade em milho. Pesquisa Agropecuária Brasileira, Brasília, v. 42, n. 2, p. 183-191, 2007.

HARTWIG, I.; OLIVEIRA, A. C.; CARVALHO, F. I. F.; BERTAN, I.; SILVA, J. A. G.; SCHMIDT, D. A. M.; VALÉRIO, I. P.; MAIA, L. C.; FONSECA, D. A. R.; REIS, C. E. S. Mecanismos associados à tolerância ao alumínio em plantas. Semina: Ciências Agrárias, Londrina, v. 28, n. 2, p. 219-228, abr./jun. 2007.

HEMP, S.; NICKNICH, W.; BACKES, R. L.; VOGT, G. A. Avaliação de variedades de milho em sistema de cultivo orgânico em Santa Catarina - Safra 2010-2011. Revista Brasileira de Agroecologia, Brasília, v. 6, n. 2, p. 1-4, 2011.

KIRCHMANN, H.; BERNAL, M. P. Organic waste treatment and C stabilization efficiency. Soil Biology Biochemistry, Kidlington, v. 29, n. 11-12, p. 1747-1753, 1997. 
MAIA, C. E.; CANTARUTTI, R. B. Acumulação de nitrogênio e carbono no solo pela adubação orgânica e mineral contínua na cultura do milho. Revista Brasileira de Engenharia Agrícola e Ambiental, Campina Grande, v. 8, n. 1, p. 39-44, 2004.

MAXTED, N.; FORD-LLOYD, B.; HAWKES, J. G. Complementary conservation strategies. In: MAXTED N.; FORD-LLOYD, B.; HAWKES, J. G. (Ed.). Plant genetic conservation: the in situ approach. London: Chapman \& Hall, 1997. p. 15-40.

PATERNIANI, M. E.A. G. Z.; FURLANI, P. R. Tolerância à toxicidade de alumínio de linhagens e híbridos de milho em solução nutritiva. Bragantia, Campinas, v. 61, n. 1, p. 11-16, 2002.

PIMENTEL-GOMES, F. Curso de estatística experimental. 13. ed. Piracicaba: Nobel, 1990. 468 p.

RABBERS, D.; TSUTSUMI, C. Y.; CHAMBÓ, E. D.; LÍRIO, F. A.; SCHOLZ, F.; LAURETH, C. V. Avaliação de variedades de milho no sistema de cultivo orgânico no município de Marechal Cândido Rondon-PR no ano agrícola 2008/2009. Revista Brasileira de Agroecologia, Brasília, v. 4, n. 2, p. 217-219, 2009.

RAO, P. S.; REDDY, P. S.; RATHORE, A.; REDDY, B. V.; PANWAR, S. Application GGE biplot and AMMI model to evaluate sweet sorghum (Sorghum bicolor) hybrids for genotype $\times$ environment interaction and seasonal adaptation. Indian Journal of Agricultural Sciences, n. 81, v. 5, p. 438-44, 2011.

SANGALLI, A.; VIEIRA, M. C.; ZÁRATE, N. A. H. Resíduos orgânicos e nitrogênio na produção de biomassa da capuchinha (Tropaeolum majus L.) Jewel. Ciência e Agrotecnologia, Lavras, v. 28, n. 4, p. 831-839, 2004.

SOARES, A. C.; MACHADO, A. T.; SILVA, B. M.; VON DER WEID, J. M. Milho crioulo, conservação e uso da biodiversidade. Rio de Janeiro: AS-PTA, 1998.

YAN, W. GGE biplot - a windows application for graphical analysis of multi-environment trial data and other types of two-way data. Agronomy Journal, Madison, v. 93, n. 5, p. 1111-1118, 2001.

YAN, W. Singular-value partitioning in biplot analysis of multienvironment trial data. Agronomy Journal, Madison, v. 94, n. 5, p. 990-996, 2002.

YAN, W.; HUNT, L. A.; SHENG, Q.; SZLAVNICS, Z. Cultivar evaluation and mega-environment investigation based on GGE biplot. Crop Science, Madison, v. 40, n. 3, p. 597-605, 2000.

YAN, W.; TINKER, A. Biplot analysis of multi environment trial data: principles and applications. Canadian Journal of Plant Science, Ottawa, v. 86, n. 3, p. 623-645, 2006. 
